University of Nebraska - Lincoln

DigitalCommons@University of Nebraska - Lincoln

Publications, Agencies and Staff of the U.S.

Department of Commerce

U.S. Department of Commerce

2012

\title{
Social network correlates of food availability in an endangered population of killer whales, Orcinus orca
}

\author{
Emma A. Foster \\ University of Exeter, emfosteruk@gmail.com \\ Daniel W. Franks \\ University of York \\ Lesley J. Morrell \\ University of Hull \\ Ken C. Balcomb \\ Center for Whale Research \\ Kim M. Parsons \\ Center for Whale Research \\ See next page for additional authors
}

Follow this and additional works at: https://digitalcommons.unl.edu/usdeptcommercepub

Part of the Environmental Sciences Commons

Foster, Emma A.; Franks, Daniel W.; Morrell, Lesley J.; Balcomb, Ken C.; Parsons, Kim M.; van Ginneken, Astrid; and Croft, Darren P., "Social network correlates of food availability in an endangered population of killer whales, Orcinus orca" (2012). Publications, Agencies and Staff of the U.S. Department of Commerce. 339.

https://digitalcommons.unl.edu/usdeptcommercepub/339

This Article is brought to you for free and open access by the U.S. Department of Commerce at DigitalCommons@University of Nebraska - Lincoln. It has been accepted for inclusion in Publications, Agencies and Staff of the U.S. Department of Commerce by an authorized administrator of DigitalCommons@University of Nebraska - Lincoln. 


\section{Authors}

Emma A. Foster, Daniel W. Franks, Lesley J. Morrell, Ken C. Balcomb, Kim M. Parsons, Astrid van Ginneken, and Darren P. Croft 


\title{
Social network correlates of food availability in an endangered population of killer whales, Orcinus orca
}

\author{
Emma A. Foster ${ }^{\mathrm{a}, \mathrm{b}, *}$, Daniel W. Franks ${ }^{\mathrm{c}}$, Lesley J. Morrell ${ }^{\mathrm{d}}$, Ken C. Balcomb ${ }^{\mathrm{b}}$, Kim M. Parsons ${ }^{\mathrm{b}, \mathrm{e}}$, \\ Astrid van Ginneken ${ }^{\text {b }}$, Darren P. Croft ${ }^{\text {a }}$ \\ ${ }^{a}$ Centre for Research in Animal Behaviour, College of Life and Environmental Sciences, Washington Singer Laboratories, University of Exeter, U.K. \\ ${ }^{\mathrm{b}}$ Center for Whale Research, Friday Harbor, WA, U.S.A. \\ ${ }^{\mathrm{c}}$ York Centre for Complex Systems Analysis, Departments of Biology E Computer Science, University of York, York, U.K. \\ ${ }^{\mathrm{d}}$ Department of Biological Sciences, University of Hull, Kingston-upon-Hull, U.K. \\ ${ }^{e}$ National Marine Mammal Laboratory, AFSC, NOAA Fisheries, Seattle, WA, U.S.A
}

\section{A R T I C L E I N F O}

\section{Article history:}

Received 18 July 2011

Initial acceptance 5 September 2011

Final acceptance 29 November 2011

Available online 20 January 2012

MS. number: 11-00573R

\section{Keywords:}

association

chinook salmon

clustering

foraging

group living

killer whale

Orcinus orca

prey

social dynamics

social organization
For the majority of social species, group composition is dynamic, and individuals are interconnected in a heterogeneous social network. Social network structure has far-reaching implications for the ecology of individuals and populations. However, we have little understanding of how ecological variables shape this structure. We used a long-term data set (1984-2007) to examine the relationship between food availability and social network structure in the endangered southern resident killer whales. During the summer months individuals in this population feed primarily on chinook salmon, Oncorhynchus tshawytscha, which show annual variation in abundance. We tested the hypothesis that temporal variation in chinook salmon will correlate with variation in social network structure. Using a null model that controlled for population demography, group size and sampling effort, we found a significant relationship between the connectivity of the social network and salmon abundance, with a more interconnected social network in years of high salmon abundance. Our results demonstrate that resource availability may be an important determinant of social network structure. Given the central importance of the social network for population processes such as the maintenance of cooperation and the transmission of information and disease, a change in social network structure caused by a change in food availability may have significant ecological and evolutionary consequences.

(c) 2012 The Association for the Study of Animal Behaviour. Published by Elsevier Ltd. All rights reserved.
For the vast majority of social species, group composition is dynamic and individuals move between social groups leading to a highly interconnected social network. Who interacts with whom and the local and global population social structures have implications for central issues in ecology and evolution (Krause \& Ruxton 2002; Croft et al. 2008). For example population social structure is central to the way animals exploit their environment (Hoelzel 1993; Baird \& Dill 1996), gene flow (Piertney et al. 1999; Matocq \& Lacey 2004; Wolf \& Trillmich 2008), frequency-dependent selection (Nowak \& May 1992; Lieberman et al. 2005), and information transfer and disease transmission (Watts \& Strogatz 1998; Cross et al. 2004). Describing the social structure of populations

\footnotetext{
* Correspondence: E. Foster, Centre for Research in Animal Behaviour, College of Life and Environmental Sciences, Washington Singer Laboratories, University of Exeter, Perry Road, Exeter EX4 4QG, U.K.

E-mail address: emfosteruk@gmail.com (E. A. Foster).
}

and unravelling the mechanisms and ecological factors underpinning this is therefore a key research focus in ecology and evolution.

Insights into the evolution of sociality have been gained by analysing social structure based on group size and composition, particularly by comparing traits among populations (or species) living under different ecological conditions (Crook 1965; Jarman 1974; Seghers 1974). This body of work has demonstrated that an important determinant of population social structure is the distribution and availability of resources. For example, the size of the group is often limited by the quality and quantity of food available (Caraco \& Wolf 1975; Baird \& Dill 1996). Such patterns have been found across a range of taxa, with groups generally being larger when food is more abundant (many antelope species: Jarman 1974; spider monkeys, Ateles geoffroyi, and chimpanzees, Pan troglodytes: Chapman et al. 1995; various primates: Janson \& Goldsmith 1995; badgers, Meles meles: Kruuk \& Parish 1982; ants, Veromessor pergandei, Pogonomyrmex rugosus, Pogonomyrmex californicus: Bernstein 1975). While such studies have focused on the level of the 
group, we know very little about how the social dynamics (e.g. the stability of social relationships) are influenced by the ecological environment and the implications of this for the social connectivity of the population.

The social organization of a population is based upon the nature and strength of interactions between individuals (Gowans et al. 2001). Using a network approach to investigate such social connectivity in populations provides us with quantitative metrics to describe the social structure at different levels of organization from the individual up to the whole population (Lusseau 2003, 2007; Lusseau \& Newman 2004; Croft et al. 2006, 2008; Madden et al. 2009). Social network analysis of animal populations has been applied in many ways; examples include disease and parasite transmission (Corner et al. 2003; Guimarães et al. 2007; Böhm et al. 2008; Godfrey et al. 2009; Drewe 2010), cooperative and behavioural assortative interactions between individuals (Croft et al. 2006, 2009), to gain understanding of social organization (Gowans et al. 2001; Leu et al. 2010), information transfer (Krützen et al. 2005; Hoppitt et al. 2010), the influence of individuals on a network (Darden et al. 2009; Jacoby et al. 2010) and the role individuals play within the network (Lusseau \& Newman 2004; Lusseau 2007). At present the relationship between the social network structure of a population and food availability is poorly understood. The little work that has been done suggests that food availability may play an important role in shaping social network structure. For example, in a study on female chacma baboons, Papio hamadryas ursinus, Henzi et al. (2009) found that when food was scarce, associations became more polarized into both constant and casual associations. In experiments on European shore crabs, Carcinus maenas, Tanner \& Jackson (2011) demonstrated that when resources were clumped individuals aggregated into cohesive, stable subgroups. Moreover, recent work on Atlantic killer whales by Beck et al. (2011) showed that the strength of associations among matrilines differed between populations that had different foraging specializations.

In this study we explored how food availability may impact population social network structure of the southern resident killer whales, which exhibit strong social bonds (Mesnick et al. 1999; Williams \& Lusseau 2006) and are organized into highly stable, matrilineal social units (Bigg et al. 1990). The southern resident killer whale community is a highly interconnected, closed population (Fig. 1), with no dispersal by males or females from the maternal group. Southern resident killer whales occur in the coastal waters of British Columbia and Washington State throughout the year; however, they are seen most frequently from

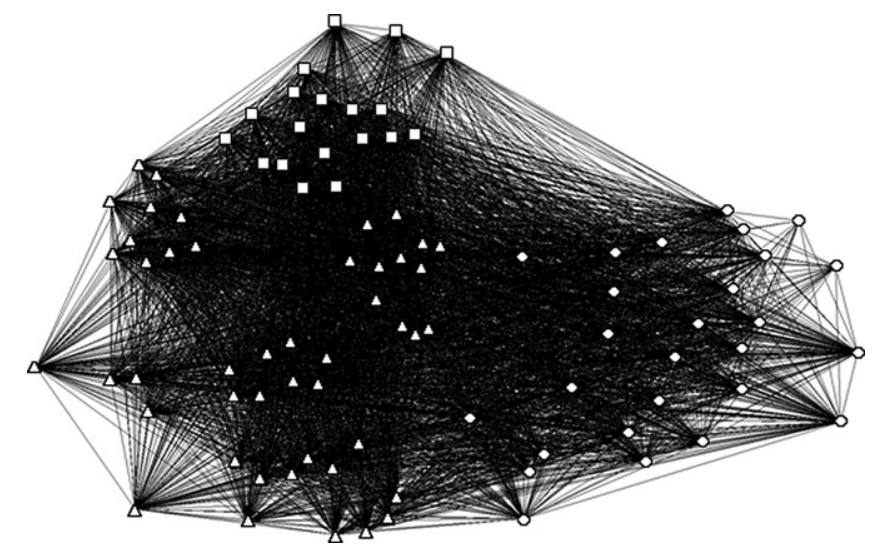

Figure 1. An example of the densely connected social network structure showing all HWI associations during the high salmon periods (15 June to 15 August) for 2007 (J pod $(O), K$ pod $(\square)$ and $L \operatorname{pod}(\Delta)$ ). Figure drawn using network visualization software, UCInet (Borgatti et al. 2002).
June to September (Fig. 2) when they feed on migrating salmonids (Olesiuk et al. 1990; Ford \& Ellis 2006). Chinook salmon, Oncorhynchus tshawytscha, comprise the largest proportion of their diet during this time, supplemented with chum salmon, Oncorhynchus keta, sockeye salmon, Oncorhynchus nerka, pink salmon, Oncorhynchus gorbuscha, ling cod, Ophiodon elongatus, and Pacific halibut, Hippoglossus stenolepis (Ford \& Ellis 2006). Recent work by Ford \& Ellis (2006) and Hanson et al. (2010) shows that from June to September chinook salmon makes up more than $90 \%$ of the southern resident killer whales' diet. There is welldocumented temporal variation in the abundance of chinook salmon (Fig. 3). These fluctuations may be caused by a combination of anthropogenic impacts and El Niño conditions affecting the survival of juvenile salmon (Slaney et al. 1996; Lackey 2003; Beacham et al. 2008). Previous research found that declines in chinook salmon abundance are correlated with reduced killer whale reproductive success (Ward et al. 2009) and higher mortality rates (Ford et al. 2010). We examined the impact that a change in food availability may have on a population's social dynamics. We predicted that in times of low salmon abundance the population will be socially fragmented, as individuals would have to spend more time foraging over a wider area, thus limiting the opportunity for social interactions.

\section{METHODS}

\section{Data Collection}

From 1984 to 2007 sightings of southern resident killer whales were documented by photographic census throughout the year by the Center for Whale Research, San Juan Island, WA, U.S.A. $\left(48.551130^{\circ} \mathrm{N}, 123.075633^{\circ} \mathrm{W}\right)$. All observations were carried out from boats ( $9 \mathrm{~m}$ trimaran and $5.5 \mathrm{~m}$ Boston Whaler). During each sampling day, every individual killer whale encountered was photographed by trained staff using Canon or Nikon SLR cameras with $300 \mathrm{~mm}$ fixed lenses (1984-2004) or with Canon or Nikon DSLR cameras with fixed $300 \mathrm{~mm}$ or $80-200 \mathrm{~mm}$ lenses (2003-2007). Sampling was limited to conditions suitable for photoidentification: no rain and relatively calm sea state (less than Beaufort 4). Individuals were identified by their unique fin shapes, saddle patches and the presence of any nicks or scratches, and sexed using the distinctive pigmentation patterns around the genital slits (Ford et al. 2000). We used data from 15 June to 15 August each year which is in the middle of the time when the chinook salmon are most abundant and form the major part of the southern resident killer whales' diet (Hanson et al. 2010). During this time observations were made on a total of 536 sampling days (mean $\pm \mathrm{SD}=22.33 \pm 9.13$ days/year) and a total of 10208 unique photographs were taken which were of sufficient quality for accurate identification. Every individual encountered was identified and included in subsequent analysis, regardless of age or sex.

Animals travelling together will usually occupy the same channels of water (i.e. will not take different routes around an island). To define social associations we followed the methods presented in Parsons et al. (2009), which recognizes that individuals within acoustic proximity have the opportunity to interact. We assumed that all animals photographed within acoustic range (approximately $10 \mathrm{~km}$; Miller 2006) were part of the same group. Every attempt was made to photograph all individuals present, which was facilitated by the fact that killer whales travel in close physical proximity (Bigg et al. 1990; Ford et al. 2000; Parsons et al. 2009).

To estimate chinook salmon abundance we used data provided by the Pacific Salmon Commission (www.psc.org). During the study period (15 June-15 August) the southern resident killer whales 


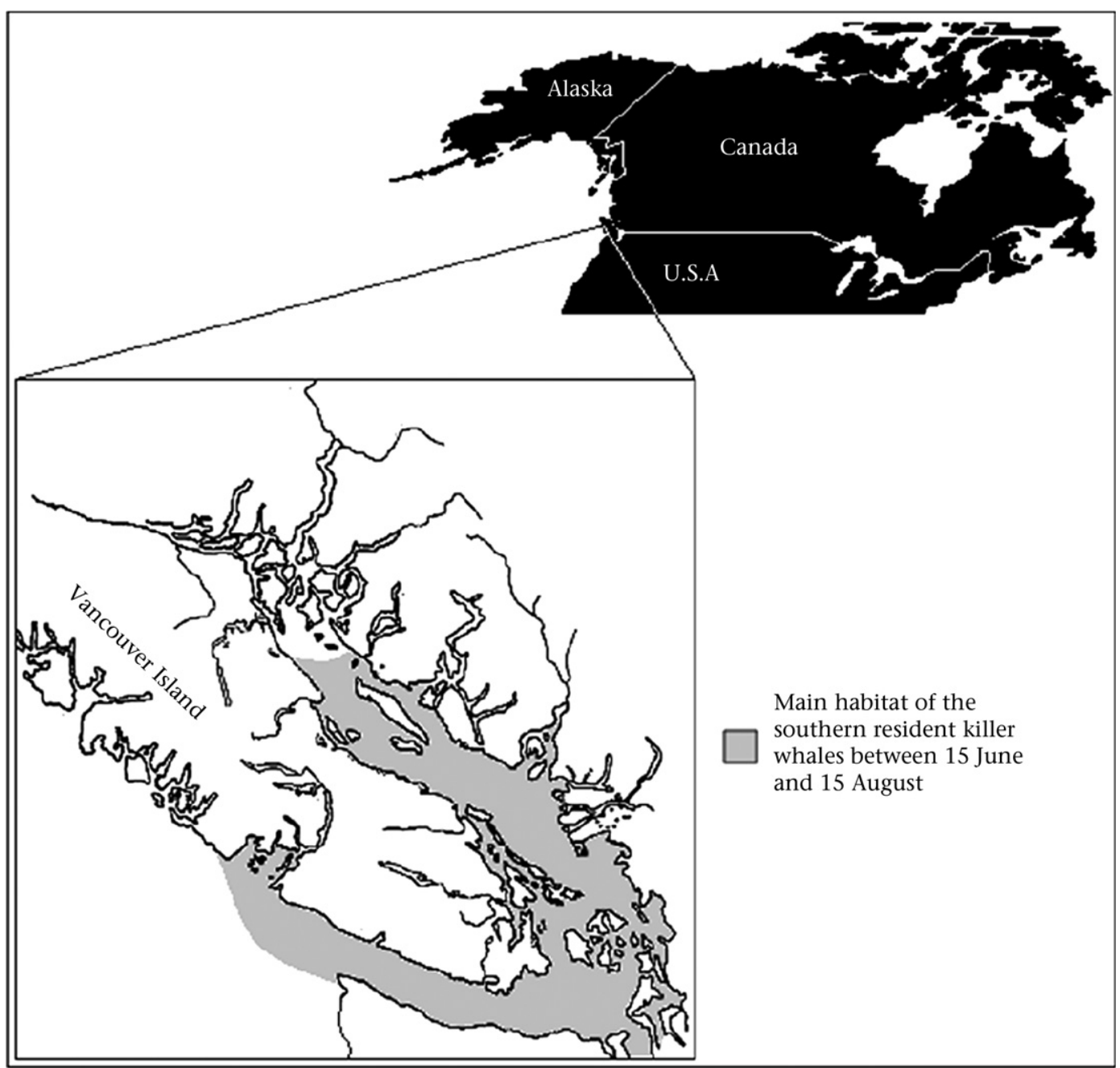

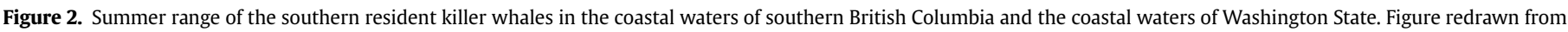
Hauser (2006).

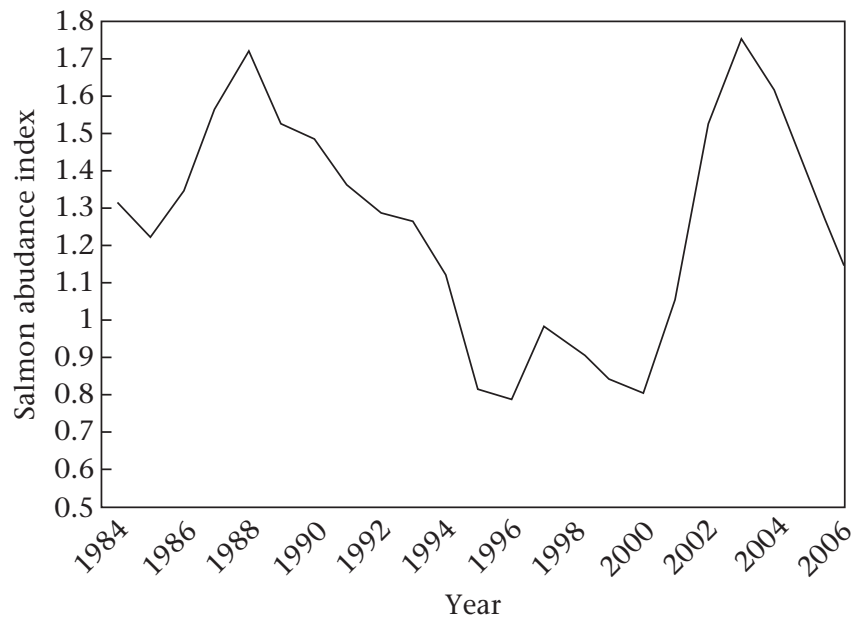

Figure 3. Chinook salmon abundance index, 1984-2006 calculated as the number of fish caught in specific areas in the Pacific North West divided by the total catch for the reference period from 1979 to 1982 (see PSC web site for full details http://www.psc. org/info.htm). Figure redrawn from data courtesy of the Pacific Salmon Commission (2008). often occur from the upper Georgia Strait to the Oregon Coast (Fig. 2) as they follow the migrating salmon. For this region we quantified the abundance of chinook salmon using catch data provided by the PSC (Fig. 3). The PSC undertake test fisheries during June to August to provide an estimate of chinook salmon abundance based on the number of fish caught, which is compared to a reference period (1979-1982; see www.psc.org for full details).

\section{Social Network Analysis}

To minimize bias from sampling techniques (Lusseau et al. 2006; Croft et al. 2008), and to maximize the comparability with other cetacean association studies (Bräger et al. 1994; Lusseau 2003; Lusseau et al. 2006; Möller et al. 2006; Williams \& Lusseau 2006; Gero et al. 2008; Beck et al. 2011), we used the half-weight index (HWI) as a measure of strength of associations between individuals (see Croft et al. 2008 for further details). Association patterns were calculated within each year from 1984 to 2007 using the HWI. Association matrices based on the HWI were calculated using SOCPROG 2.4 (Whitehead 2009).

For each annual configuration we quantified both global and local population structure using weighted network measures (Lusseau et al. 2008). To quantify the global connectivity of the population we used the average weighted path length $(L)$, which is 
defined as the shortest distance from an individual to the rest; a shorter path length may result in faster information or disease transfer between individuals. To quantify the local population structure we used the weighted clustering coefficient $(C)$, which is defined as the connectivity between an individual's neighbours; a high clustering means that the social network is highly interconnected on a local scale. We also calculated average weighted degree centrality $(k)$, which is defined as the sum of the strength of the associations that an individual has and the mean HWI for the network, which provides a measure of the average strength of association. All network measures were calculated in R using the tnet library (Opsahl 2009).

As the social network measures that describe the global and local population structure are not independent (Croft et al. 2008) we combined the measures using a principal components analysis (PCA). To determine which component(s) to use in the analysis we used the Kaiser-Guttman criterion, where we calculated the eigenvalues for each component of the PCA, and included components with an eigenvalue greater than one (Jackson 1993). We first explored the effect of salmon abundance on population and group size, and population and group size on social network PCA score, using a Spearman rank correlation. We then used a Spearman rank correlation to examine the relationship between the PCA of the network measures and chinook salmon abundance. To account for autocorrelations in our network data, and to control for group size distributions, demographic effects and sampling, we used a randomization test to calculate significance (Bräger et al. 1994; Whitehead 1999; Croft et al. 2011). This was performed on the group-based data using swaps of individuals between groups within each sampling year, before calculating a Spearman rank correlation for that data for each randomization. Five thousand randomizations were generated with 100 swaps per randomization. Randomizations were programmed in $\mathrm{c}++$ (www.cplusplus.com).

\section{Ethical Note}

From 1984 to 2004, the data were collected under whale watch guidelines that are endorsed by the governments of the U.S.A. and Canada in lieu of a regulatory scheme; it is not considered invasive or illegal to watch whales in either country. From 2005 onwards, we operated under federal permits (MMPA permit number 532-1822 and/or DFO licence number 2006-08/SARA-34) in both the U.S.A. and Canada that allowed approaches closer than the whale watch guidelines (100 m approach distance) on a specified number of occasions for research purposes. We complied with the approach guidelines and the requirements (including reporting) of the scientific permits issued to us.

\section{RESULTS}

There were 168 individuals ( 80 females, 69 males and 18 individuals of unknown sex) documented during the 24 -year period. The population size in any given year ranged from 71 to 98 (mean $\pm \mathrm{SD}=85 \pm 6.6$ ).

Component 1 of the PCA was the only component with an eigenvalue greater than 1 (3.72), so we retained this component, which described $93.1 \%$ of the variance and was used for all subsequent analysis. Clustering coefficient, degree centrality and mean HWI all loaded positively onto the PCA $(0.491,0.500,0.511$, respectively), while path length loaded negatively $(-0.498)$. Thus a high PCA score indicates a high clustering coefficient, degree centrality and mean HWI, and a low path length.

We found no significant relationship between salmon abundance and population size $\left(r_{\mathrm{S}}=-0.307, N=24, P=0.154\right)$ or between population size and social network PCA score $\left(r_{\mathrm{S}}=0.074\right.$,
$N=24, P=0.738)$. However, there was a significant positive relationship between salmon abundance and group size $\left(r_{\mathrm{S}}=0.457\right.$, $N=24, P=0.025)$ and group size and social network PCA score $\left(r_{\mathrm{S}}=0.686, N=24, P<0.001\right)$. In times of high salmon abundance groups tended to be larger, which is reflected in the social network as higher clustering coefficient, degree centrality and mean HWI, and a lower path length. We controlled for these relationships with our randomizations.

Group-based randomizations (controlling for group size effects, demographics and sampling effort) showed a significant relationship between the social network structure and chinook salmon abundance during the study period $\left(r_{\mathrm{S}}=0.412, N=24, P=0.020\right.$; Fig. 4). In years of high chinook salmon abundance the social network exhibited a high clustering coefficient, degree centrality and mean HWI, and a low path length (Fig. 4).

\section{DISCUSSION}

Based on the analysis of association data over a 24-year period, our results demonstrate a significant relationship between social network structure and food availability. In times of high chinook salmon abundance the southern resident killer whale population is characterized by a highly interconnected social network with a high clustering coefficient, degree centrality and mean HWI, and a low path length. This relationship is not simply an effect of population demography, group size or sampling effort, all of which were controlled for in our analysis. To the best of our knowledge this study is the first to examine the relationship between resource availability and both the local and global connectivity of the population social network structure in a free-ranging population.

It is well documented that resource availability can lead to changes in group size (Jarman 1974; Bernstein 1975; Caraco \& Wolf 1975; Kruuk \& Parish 1982; Clark \& Mangel 1984; Chapman et al. 1995; Janson \& Goldsmith 1995; Baird \& Dill 1996). We found a significant relationship between salmon abundance and group size, with larger groups forming in years of high salmon abundance. We would expect to see this, as more abundant food resources can support larger groups, with reduced competition (Chapman et al. 1995; Krause \& Ruxton 2002). Group size also had a significant effect on the population social network structure and when the mean group size was small the social network had low clustering coefficient, degree centrality, mean HWI and a high path length.

We found an effect of salmon abundance on the social network structure over and above the effects that could be explained by variation in group size. In times of low salmon abundance the

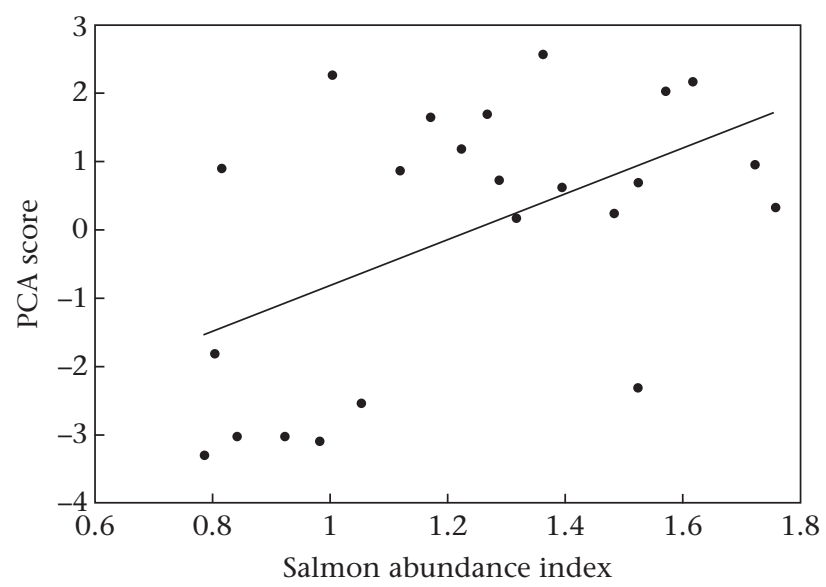

Figure 4. Relationship between PCA score of network measures and chinook salmon abundance from 1984 to 2007 
population was characterized by a less connected social network than in times of high salmon abundance. Killer whales benefit from cooperative food searching; however, they are not thought to hunt cooperatively (Baird 2000). Beck et al. (2011) demonstrated that killer whale family groups remain stable over time, regardless of their prey choice; however, our results suggest that the social connectivity both within and among groups is affected by prey availability. We suggest that our results are influenced in part by a trade-off between foraging effort and social activity. Thus in periods of low salmon abundance increased time spent searching for prey may reduce the opportunity for social interactions within the group. Reduced time for social interactions is also indicated by a significant decline in the rate of association among whales during years of low salmon abundance (Parsons et al. 2009). In support of this suggestion previous work has demonstrated that when prey are scarce or patchily distributed, killer whales not only have to invest more time in locating prey, they also spend more time spread out, away from the rest of the group (Felleman et al. 1991). In addition, killer whales have been observed travelling much further during times of low food availability (Nichol \& Shackleton 1996). This behavioural adaptation has also been observed in long- and short-finned pilot whales, Globicephala melas and Globicephala macrorhynchus, sperm whales, Physeter macrocephalus (Whitehead 1989), common dolphins, Delphinus spp., spotted dolphins, Stenella frontalis, and spinner dolphins, Stenella longirostris (Norris \& Dohl 1980). Similar patterns have also been observed in terrestrial animals such as insectivorous primates (Janson \& Goldsmith 1995) and elephants, Loxodonta africana (Wittemyer et al. 2005). Our results suggest that low food abundance limits the opportunity for social interactions; however, there are exceptions to this. For example, in a study on female chacma baboons, Henzi et al. (2009) observed cyclic changes in the patterns of interaction with an increase in the strength of social bonds during times of low food availability.

The changes we observed in social network structure in the current study are only partly explained as a function of food availability. We found no relationship between salmon abundance and population size or population size and social network. Previous work suggests that there may be a lagged impact of food availability on population size. This has been shown for the northern and southern resident killer whale populations in terms of both survival (Ford et al. 2010) and fecundity (Ward et al. 2009). A number of other ecological factors that were not measured may have had an impact on the structuring of the population social network. In particular, the distribution of resources may have had a strong influence on the opportunities for social interactions (Tanner \& Jackson 2011).

Changes in social structure may have significant implications for population processes such as information and disease transmission (Krause \& Ruxton 2002; Croft et al. 2008). Nonrandom networks with high clustering and short path length have been shown to be susceptible to disease outbreaks (Guimarães et al. 2007). The southern resident killer whales, in times of low chinook salmon abundance when the population is less interconnected, may be less vulnerable to an epidemic outbreak. This may be particularly important, as in times of low food availability individuals metabolize fat which releases pollutants such as polychlorinated biphenyls resulting in increased susceptibility to disease (Ford et al. 2010). When food is abundant, the southern resident killer whale social network is highly connected, which may provide a number of benefits including increased opportunities for mating and information transfer (Croft et al. 2008).

The predominant application of social network analysis to nonhuman animals has been to investigate the internal factors affecting social dynamics (e.g. Parsons et al. 2003; Croft et al. 2005;
Williams \& Lusseau 2006). Our investigation demonstrates the potential of using a network approach to investigate the relationship between the ecological environment and population social dynamics. This approach is applicable to other species, and such understanding is invaluable when designing effective conservation and management plans.

\section{Acknowledgments}

We acknowledge funding from the BBSRC and the Center for Whale Research. We thank the PSC for provision of the salmon abundance data, and 30 years of staff and Earthwatch volunteers. We also thank three referees whose comments greatly improved the manuscript.

\section{References}

Baird, R. W. 2000. The killer whale: foraging specialisations and group hunting In: Cetacean Societies (Ed. by J. Mann, R. Connor, P. L. Tyack \& H. Whitehead), pp. 127-153. Chicago: University of Chicago Press.

Baird, R. W. \& Dill, L. M. 1996. Ecological and social determinants in group size in transient killer whales. Behavioral Ecology, 7, 408-416.

Beacham, T. D., Winther, I., Jonsen, K. L., Wetklo, M., Deng, L. \& Candy, J. R. 2008. The application of rapid microsatellite-based stock identification to management of a chinook salmon troll fishery off the Queen Charlotte Islands, British Columbia. North American Journal of Fisheries Management, 28, 249-855.

Beck, S., Kuningas, S., Esteban, R. \& Foote, A. D. 2011. The influence of ecology on sociality in the killer whale (Orcinus orca). Behavioral Ecology, published online 10 October 2011, doi:10.1093/beheco/arr1151.

Bernstein, R. A. 1975. Foraging strategies of ants in response to variable food density. Ecology, 56, 213-219.

Bigg, M. A., Olesiuk, P. F., Ellis, G. M., Ford, J. K. B. \& Balcomb, K. C. 1990. Social organization and geneology of resident killer whales (Orcinus orca) in the coastal waters of British Columbia and Washington State. Report of the International Whaling Commission, 12, 383-405.

Böhm, M., Palphramand, K. L., Newton-Cross, G., Hutchings, M. R. \& White, P. C. L. 2008. Dynamic interactions among badgers: implications for sociality and disease transmission. Journal of Animal Ecology, 77, 735-745.

Borgatti, S. P., Everett, M. G. \& Freeman, L. C. 2002. Ucinet for Windows: Software for Social Network Analysis. Harvard, Massachusetts: Analytic Technologies.

Bräger, S., Würsig, B., Acevedo, A. \& Henningsen, T. 1994. Association patterns of bottlenose dolphins (Tursiops truncatus) in Galveston Bay, Texas. Journal of Mammalogy, 75, 431-437.

Caraco, T. \& Wolf, L. L. 1975. Ecological determinants of group sizes of foraging lions. American Naturalist, 109, 343-352.

Chapman, C. A., Wrangham, R. W. \& Chapman, L. J. 1995. Ecological constraints on group size: an analysis of spider monkey and chimpanzee subgroups. Behavioral Ecology and Sociobiology, 36, 59-70.

Clark, C. W. \& Mangel, M. 1984. Foraging and flocking strategies: information in an uncertain environment. American Naturalist, 123, 626-641.

Corner, L. A. L., Pfeiffer, D. U. \& Morris, R. S. 2003. Social-network analysis of Mycobacterium bovis transmission among captive brushtail possums (Trichosurus vulpecula). Preventive Veterinary Medicine, 59, 147-167.

Croft, D. P., James, R., Ward, A. J. W., Botham, M. S., Mawdsley, D. \& Krause, J. 2005. Assortive interactions and social networks in fish. Oecologia, 143, 211-219.

Croft, D. P., James, R., Thomas, P. O. R., Hathaway, C., Mawdsley, D., Laland, K. N. \& Krause, J. 2006. Social structure and co-operative interactions in a wild population of guppies (Poecilia reticulata). Behavioral Ecology and Sociobiology, 59, 644-650.

Croft, D. P., James, R. \& Krause, J. 2008. Exploring Animal Social Networks. Princeton, New Jersey: Princeton University Press.

Croft, D. P., Krause, J., Darden, S. K., Ramnarine, I. W., Faria, J. J. \& James, R. 2009. Behavioural trait assortment in a social network: patterns and implications. Behavioral Ecology and Sociobiology, 63, 1495-1503.

Croft, D. P., Madden, J. R., Franks, D. W. \& James, R. 2011. Hypothesis testing in animal social networks. Trends in Ecology \& Evolution, 26, 502-507.

Crook, J. H. 1965. The adaptive significance of avian social organisations. Symposium of the Zoological Society of London, 14, 253-266.

Cross, P. C., Lloyd-Smtih, J. O., Bowers, J. A., Hay, C. T., Hofmeyer, M. \& Getz, W. M. 2004. Integrating association data and disease dynamics in a social ungulate: bovine tuberculosis in African buffalo in the Kruger National Park. Annales Zoologici Fennici, 41, 879-892.

Darden, S. K., James, R., Ramnarine, I. W. \& Croft, D. P. 2009. Social implications of the battle of the sexes: sexual harassment disrupts female sociality and social recognition. Proceedings of the Royal Society B, 276, 2651-2656.

Drewe, J. A. 2010. Who infects whom? Social networks and tuberculosis transmission in wild meerkats. Proceedings of the Royal Society B, 277, 633-642.

Felleman, F. L., Heimlich-Boran, J. R. \& Osborne, R. W. 1991. The feeding ecology of killer whales (Orcinus orca) in the Pacific Northwest. In: Dolphin Societies. 
Discoveries and Puzzles (Ed. by K. Pryor \& K. Norris), pp. 113-147. Berkeley: University of California Press.

Ford, J. K. B. \& Ellis, G. M. 2006. Selective foraging by fish-eating killer whales (Orcinus orca) in British Columbia. Marine Ecology Progress Series, 316, 185-199.

Ford, J. K. B., Ellis, G. M. \& Balcomb, K. C. 2000. Killer Whales: The Natural History and Genealogy of Orcinus orca in British Columbia and Washington State. Vancouver: University of British Columbia Press.

Ford, J. K. B., Ellis, G. M., Olesiuk, P. F. \& Balcomb, K. C. 2010. Linking killer whale survival and prey abundance: food limitation in the oceans' apex predator? Biology Letters, 6, 139-142.

Gero, S., Engelhaupt, D. \& Whitehead, H. 2008. Heterogeneous social associations within a sperm whale, Physeter macrocephalus, unit reflect pairwise relatedness. Behavioral Ecology and Sociobiology, 63, 143-151.

Godfrey, S. S., Bull, C. M., James, R. \& Murray, K. 2009. Network structure and parasite transmission in a group living lizard, the gidgee skink, Egernia stokesii. Behavioral Ecology and Sociobiology, 63, 1045-1056.

Gowans, S., Whitehead, H. \& Hooker, S. K. 2001. Social organization in northern bottlenose whales, Hyperoodon ampullatus: not driven by deep-water foraging? Animal Behaviour, 62, 369-377.

Guimarães, P. R., Argollo de Menezes, M., Baird, R. W., Lusseau, D., Guimarães, P. \& dos Reis, S. F. 2007. Vulnerability of a killer whale social network to disease outbreaks. Physical Review E, 76, 1-4.

Hanson, M. B., Baird, R. W., Ford, J. K. B., Hempelmann-Halos, J., Van Doornick, D. M., Candy, J. R., Emmons, C. K., Schorr, G. S., Gisborne, B. \& Ayres, K. L., et al. 2010. Species and stock identification of prey consumed by endangered southern resident killer whales in their summer range. Endangered Species Research, 11, 69-82.

Hauser, D. D. W. 2006. Summer space use of southern resident killer whales (Orcinus orca) within Washington and British Columbia inshore waters. Ph.D. thesis, University of Washington.

Henzi, S. P., Lusseau, D., Weingrill, T., Van Schaik, C. P. \& Barrett, L. 2009. Cyclicity in the structure of female baboon social networks. Behavioral Ecology and Sociobiology, 63, 1015-1021.

Hoelzel, A. R. 1993. Foraging behaviour and social group dynamics in Puget Sound killer whales. Animal Behaviour, 45, 581-591.

Hoppitt, W., Boogert, N. J. \& Laland, K. N. 2010. Detecting social transmission networks. Journal of Theoretical Biology, 263, 544-555.

Jackson, D. A. 1993. Stopping rules in principal components analysis: a comparison of heuristical and statistical approaches. Ecology, 74, 2204-2214.

Jacoby, D. M. P., Busawon, D. S. \& Sims, D. W. 2010. Sex and social networking: the influence of male presence on social structure of female shark groups. Behavioral Ecology, 21, 808-818.

Janson, C. H. \& Goldsmith, M. L. 1995. Predicting group size in primates: foraging costs and predation risks. Behavioral Ecology, 6, 326-336.

Jarman, P. J. 1974. Social organisation of antelope in relation to their ecology. Behaviour, 48, 215-267.

Krause, J. \& Ruxton, G. D. 2002. Living in Groups. Oxford: Oxford University Press.

Krützen, M., Mann, J., Heithaus, M. R., Connor, R. C., Bejder, L. \& Sherwin, W. B. 2005. Cultural transmission of tool use in bottlenose dolphins. Proceedings of the National Academy of Sciences, U.S.A., 102, 8939-8943.

Kruuk, H. \& Parish, T. 1982. Factors affecting population density, group size and territory size of the European badger, Meles meles. Journal of Zoology, 196, $31-39$.

Lackey, R. T. 2003. Pacific Northwest salmon: forecasting their status in 2100. Reviews in Fisheries Science, 11, 35-88.

Leu, S. T., Bashford, J., Kappeler, P. M. \& Bull, C. M. 2010. Association networks reveal social organization in the sleepy lizard. Animal Behaviour, 79, 217-225.

Lieberman, E., Hauert, C. \& Nowak, M. A. 2005. Evolutionary dynamics on graphs. Nature, 433, 312-316.

Lusseau, D. 2003. The emergent properties of a dolphin social network. Biology Letters, 270, S186-S188.

Lusseau, D. 2007. Evidence for social role in a dolphin social network. Evolutionary Ecology, 21, 357-366.

Lusseau, D. \& Newman, M. E. J. 2004. Identifying the role that animals play in their social networks. Biology Letters, 217, S477-S481.
Lusseau, D., Wilson, B., Hammond, P. S., Grellier, K., Durban, J. W., Parsons, K. M., Barton, T. R. \& Thompson, P. M. 2006. Quantifying the influence of sociality on population structure in bottlenose dolphins. Journal of Animal Ecology, 75, 14-24.

Lusseau, D., Whitehead, H. \& Gero, S. 2008. Incorporating uncertainty into the study of animal social networks. Animal Behaviour, 75, 1809-1815.

Madden, J. R., Drewe, J. A., Pearce, G. P. \& Clutton-Brock, T. H. 2009. The socia network structure of a wild meerkat population: 2. Intergroup interactions. Behavioral Ecology and Sociobiology, 64, 81-95.

Matocq, M. D. \& Lacey, E. A. 2004. Philopatry, kin clusters, and genetic relatedness in a population of woodrats (Neotoma macrotis). Behavioral Ecology, 15, 647-653.

Mesnick, S. L., Taylor, B. L., le Duc, R. G., Treviño, S. E., O’Corry-Crowe, G. M. \& Dizon, A. E. 1999. Culture and genetic evolution in whales. Science, 284, 2055.

Miller, P. J. O. 2006. Diversity in sound pressure levels and estimated active space of resident killer whale vocalizations. Journal of Comparative Psychology A, 192, 449-459.

Möller, L. M., Beheregaray, L. B., Allen, S. J. \& Harcourt, R. G. 2006. Association patterns and kinship in female Indo-Pacific bottlenose dolphins (Tursiops aduncus) of southeastern Australia. Behavioral Ecology and Sociobiology, 61, 109-117.

Nichol, L. M. \& Shackleton, D. M. 1996. Seasonal movements and foraging behavior of northern resident killer whales in relation to the inshore distribution of salmon (Oncorhynchus spp.) in British Columbia. Canadian Journal of Zoology, 74 983-991.

Norris, K. S. \& Dohl, T. P. 1980. Behaviour of the the Hawaiian spinner dolphin, Stenella longirostris. Fisheries Bulletin, 77, 821-849.

Nowak, M. A. \& May, R. M. 1992. Evolutionary games and spatial chaos. Nature, 441 502-505.

Olesiuk, P. F., Bigg, M. A. \& Ellis, G. M. 1990. Life history and population dynamics of resident killer whales (Orcinus orca) in coastal waters of British Columbia and Washington State. Report of the International Whaling Commission, 12, 209-243.

Opsahl, T. 2009. Structure and evolution of weighted networks. Ph.D. thesis, University of London.

Parsons, K. M., Durban, J. W., Claridge, D. E., Balcomb, K. C., Noble, L. R. \& Thompson, P. M. 2003. Kinship as a basis for alliance formation between male bottlenose dolphins, Tursiops truncatus, in the Bahamas. Animal Behaviour, 66, 185-194.

Parsons, K. M., Balcomb, K. C., Ford, J. K. B. \& Durban, J. W. 2009. The socia dynamics of southern resident killer whales and conservation implications for this endangered population. Animal Behaviour, 77, 963-971.

Piertney, S. B., MacColl, A. D. C., Lambin, X., Moss, R. \& Dallas, J. F. 1999. Spatial distribution of genetic relatedness in a moorland population of red grouse (Lagopus lagopus scoticus). Biological Journal of the Linnean Society, 68, 317-331.

Seghers, B. H. 1974. Schooling behavior in the guppy (Poecilia reticulata): an evolutionary response to predation. Evolution, 28, 486-489.

Slaney, T. L., Hyatt, K. D., Northcote, T. G. \& Fieldon, R. J. 1996. Status of anadromous salmon and trout in British Columbia and Yukon. Fisheries, 21, 20-35.

Tanner, C. J. \& Jackson, A. L. 2011. Social structure emerges via the interaction between local ecology and individual behaviour. Journal of Animal Ecology, published online 13 June 2011, doi:10.1111/j.1365-2656.2011.01879.x.

Ward, E. J., Holmes, E. E. \& Balcomb, K. C. 2009. Quantifying the effects of prey abundance on killer whale reproduction. Journal of Applied Ecology, 46, 632-640.

Watts, D. J. \& Strogatz, S. H. 1998. Collective dynamics of 'small-world' networks. Nature, 393, 440-442.

Whitehead, H. A. L. 1989. Foraging formations of Galápagos sperm whales whales Canadian Journal of Zoology, 67, 2131-2139.

Whitehead, H. A. L. 1999. Testing association patterns of social animals. Animal Behaviour, 57, F26-F29.

Whitehead, H. A. L. 2009. SOCPROG programs: analysing animal social structures. Behavioral Ecology and Sociobiology, 63, 765-778.

Williams, R. \& Lusseau, D. 2006. A killer whale social network is vulnerable to targeted removals. Biology Letters, 2, 497-500.

Wittemyer, G., Douglas-Hamilton, I. \& Getz, W. M. 2005. The socioecology of elephants: analysis of the processes creating multitiered social structures. Animal Behaviour, 69, 1357-1371.

Wolf, J. B. W. \& Trillmich, F. 2008. Kin in space: social viscosity in a spatially and genetically substructured network. Proceedings of the Royal Society B, 275 2063-2069. 